\title{
Características agronômicas de cultivares de mamona em função do local de cultivo e da época de semeadura no Rio Grande do Sul
}

\author{
Characteristics of castor bean cultivars according to the environmental crop and sowing season \\ in Rio Grande do Sul State, Brazil
}

\author{
Jacson Zuchi' Gilberto Antônio Peripolli Bevilaqua' ${ }^{\mathrm{II}}$ José Cola Zanuncio ${ }^{\mathrm{III}}$ \\ Silmar Teichert Peske ${ }^{\mathrm{IV}}$ Sérgio Delmar dos Anjos e Silva ${ }^{\mathrm{II}}$ Carlos Sigueyuki SediyamaII
}

\section{RESUMO}

A mamona (Ricinus communis L.) é uma planta oleaginosa anual e, ocasionalmente, bienal em regiões tropicais, com ciclo médio de 150 dias para a maioria das cultivares anuais e de 120 a 130 dias para cultivares anuais precoces. $O$ objetivo deste trabalho foi avaliar características agronômicas de cultivares das mamonas 'Al Guarany 2002', 'IAC 80', 'IAC 226'e 'BRS 188 Paraguaçu'em função do ambiente de cultivo e da época de semeadura. As cultivares foram semeadas entre o primeiro e o quinto dia dos meses de novembro e dezembro, na Embrapa Clima Temperado, em Pelotas, Rio Grande do Sul. Cada época teve 12 unidades experimentais em três blocos casualizados. A emergência, a altura de planta $e$ de inserção do primeiro cacho, o período de florescimento e colheita e o ataque de pragas e doenças foram avaliados e analisados com o programa WinStat Versão 2.0. O comportamento entre as cultivares diferiu entre locais de cultivo e época de semeadura. A inserção do cacho foi mais alta, e as florações e colheitas foram mais tardias em plantas da segunda época de semeadura. Danos por pragas e doenças e os descritores morfológicos da planta de mamona apresentaram diferenças entre os locais de cultivo.

Palavras-chave: altura, floração, pragas.

\section{ABSTRACT}

Castor bean (Ricinus communis L.) is an oleaginous plant with annual cycle and occasionally biennial cycle in tropical areas, with mean cycle of 150 days for the majority of annual cultivars and 120 to 130 days for annual early cultivars. The objective of this study was to evaluate the agronomic characteristics of castor cultivars according to environmental crop and sowing season. The experiment was conduced at Embrapa Clima Temperado - Pelotas/RS, in two places. The castor cultivars used in this research were 'Al Guarany 2002', 'IAC 80', 'IAC 226' and 'BRS 188 Paraguaçu', which were sown in two sowing times: the first was in early November (between $1^{\text {st }}$ and $5^{\text {st }}$ ) and the second was in early December (between $1^{\text {st }}$ and $\left.5^{\text {st }}\right)$. Each sowing season was constituted of 12 experimental units, distributed in three random blocks. It was evaluated the emergency, plant height and first spike insertion, flowering and harvest time, pest and disease attacks. The WinStat program Version 2.0 was used for data statistical analysis. There was a significant difference among cultivar behaviors between the environmental crops and sowing seasons. The second sowing season provided a larger plant and first spike insertion was higher. It also promoted retardation in the flowering and harvesting time. The differences among cultivars, between the two environmental crops, were clearer in the pest and disease attacks, but also in morphologic characteristics of castor plant.

Key words: height, flowering time, pest.

\section{INTRODUÇÃO}

O uso de sementes de boa qualidade é o aspecto mais importante da cadeia produtiva da mamona (QUEIROGA \& SANTOS, 2008). A maioria dos produtores de mamona do nordeste brasileiro (84\%) consorcia essa oleaginosa com outras culturas (QUEIROGA \& SANTOS, 2008), mas sua

\footnotetext{
IDepartamento de Fitotecnia, Universidade Federal de Viçosa (UFV), 36570-000, Viçosa, MG, Brasil. E-mail: jacson.zuchi@ufv.br. Autor para correspondência.

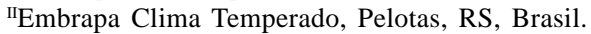

IIIDepartamento de Fitotecnia, UFV, Viçosa, MG, Brasil.

${ }^{\text {IV }}$ Departamento de Fitotecnia, Universidade Federal de Pelotas (UFPel), Pelotas, RS, Brasil.
} 
produção decresce como o aumento da população da cultura consorte (AZEVEDO et al., 2007). A distribuição longitudinal de plantas de mamona também influencia parâmetros fitotécnicos, inclusive a produtividade dessa cultura (RAMOS et al., 2008).

A ordem floral, a época de semeadura e as características de cada cultivar provocam variações na contribuição de cada cacho para a produtividade total da cultura (VIJAYA KUMAR et al., 1997; KOUTROUBAS et al., 2000). O primeiro cacho de mamona é mais produtivo (VIJAYA KUMAR et al., 1997), mas a segunda floração tem maior produtividade (SAVY FILHO et al., 1990, CORRÊA et al., 2006). A mamoneira apresenta flores masculinas e femininas em uma mesma inflorescência, mas em posições diferentes (BELTRÃO et al., 2001), e sua expressão é controlada, principalmente, por giberelinas e citocininas (KHRYANIN, 2002). O zoneamento agrícola da mamona é baseado na pluviosidade, temperatura média e altitude (AMORIM NETO et al., 2001) e por isso a adequação de época de semeadura é necessária por região.

O programa de biodiesel brasileiro incentiva o uso de culturas que possibilitem a inserção de agricultores familiares neste programa, e a cultura da mamona se destaca pelo seu alto teor de oleo e pela qualidade deste como combustivel, além de ser um cultivo que possibilita a participação de produtores menos capitalizados. Entretanto, há uma grande carência de materiais genéticos altamente produtivos, e as cultivares disponíveis não foram amplamente testadas no território nacional. Desse modo, o zoneamento agrícola de cultivares de mamona e o conhecimento de suas características agronômicas possibilitarão a difusão de tecnologia adequada a cada região, facilitando e maximizando a produção dessa cultura pelos produtores.

O objetivo deste estudo foi avaliar as características agronômicas de cultivares de mamona em função do ambiente de cultivo e da época de semeadura.

\section{MATERIAL E MÉTODOS}

O experimento foi conduzido em dois locais: o local 1 apresentava argissolo amarelo, latitude $31^{\circ} 40^{\prime}$ 53,6”'S, longitude $52^{\circ} 26^{\prime}$ 23,5”'W e altitude de 67,1 metros, e o local 2 apresentava argissolo vermelho, latitude $31^{\circ}$ 37' 16”, longitude 52 $31^{\prime}$ '40” e altitude de $190 \mathrm{~m}$ das Estações Sede e Cascata de Pesquisa da Embrapa Clima Temperado em Pelotas, Rio Grande do Sul.
As cultivares de mamona utilizadas foram as 'Al Guarany' 2002', 'IAC 80', 'IAC 226' e 'BRS 188 Paraguaçu’, cujas produtividade, adaptação e época de semeadura estão sendo avaliadas no Estado do Rio Grande do Sul. As cultivares de mamona diferem em ciclo, porte e deiscência das vagens. 'Al Guarany 2002' e 'IAC 226' têm ciclo de 180 dias, porte médio e fruto indeiscente; 'IAC 80' tem ciclo de 240 dias, porte alto e frutos semideiscentes, e 'BRS 188 Paraguaçu' tem porte médio/alto e frutos semideiscentes.

Em cada local, o experimento foi arranjado em um fatorial 4x2 (quatro cultivares e duas épocas de semeadura), em três repetições, no delineamento de blocos ao acaso, totalizando 24 unidades experimentais. Cada época de semeadura teve 12 unidades experimentais, quatro por bloco, cada uma com seis metros de largura e três metros de comprimento, perfazendo cinco fileiras de plantas por parcela. Cada unidade experimental teve uma área de $30 \mathrm{~m}^{2}$, com 30 plantas em cinco linhas. A unidade de observação foi o centro de cada parcela, nas três linhas centrais, com área de $7,5 \mathrm{~m}^{2}$ e 10 plantas.

As cultivares de mamona foram semeadas entre o primeiro e o quinto dia dos meses de novembro e dezembro, correspondendo à $1^{\mathrm{a}} \mathrm{e}$ à $2^{\mathrm{a}}$ época de semeadura, respectivamente. Três sementes de cada cultivar foram semeadas por cova com adubo NPK, fórmula 10-30-10, na dosagem de $400 \mathrm{~kg} \mathrm{ha}^{-1}$ de base. O espaçamento de plantio foi de $1,0 \mathrm{~m}$ entre plantas e $1,20 \mathrm{~m}$ entre linhas, com uma população de 8,333 plantas ha-1.

A produção foi acompanhada até o terceiro cacho, quando as plantas terminaram seu ciclo, no final de junho. Os cachos foram colhidos e depositados em sacos de fibra, porosos e identificados por cultivar, ordem do cacho, número de plantas colhidas e data da colheita.

A emergência, data em que 50\% das plântulas da parcela estavam com os cotilédones na posição horizontal, a altura de inserção do primeiro cacho, a altura de planta, o número de cachos por planta, o número de cachos por floração e a data de emissão dos cachos florais foram avaliados por unidade experimental, época de semeadura e local de cultivo. A data de floração foi considerada quando $50 \%$ das plantas da parcela se encontravam em antese. A altura de inserção do primeiro cacho e altura da planta até a inserção da última folha foram obtidas pela medição de 10 plantas das três linhas centrais da parcela, com régua centimétrica aos 120 dias após 
a emergência das plântulas. O número de cachos por planta e por floração foi obtido pela contagem do número de inflorescências de 10 plantas de três fileiras centrais da parcela e, consecutivamente, a colheita foi realizada quando $50 \%$ das plantas por parcela se encontravam com $70 \%$ dos cachos secos.

A percentagem de ataque de pragas (percevejos), doenças de cacho (mofo-cinzento), doenças foliares (mancha de cercospora) e doenças de raiz (fusariose) foi obtida por avaliação visual individual do órgão atacado de 10 plantas das três fileiras centrais de cada parcela.

Os dados do experimento foram analisados separadamente por local, com o programa de análise estatística para o Windows - WinStat versão 2.0 (MACHADO \& CONCEIÇÃO, 2003), sem a transformação dos dados originais, e as médias foram comparadas por cultivar, por meio do teste de Tukey, com probabilidade de 5\% de erro.

\section{RESULTADOS E DISCUSSÃO}

A época de semeadura afetou o comportamento das cultivares, a emergência, a altura das plantas e a de inserção do primeiro cacho floral em plantas de mamona. A emergência, na segunda época de semeadura de todas as cultivares, apresentou antecipação significativa aos 15 dias na primeira época e 12 dias na segunda. A altura das plantas de mamona foi maior que dois metros na segunda época de semeadura nas quatro cultivares, enquanto na primeira isso não ultrapassou dois metros (Tabela 1). A redução da altura das plantas não afetou a produtividade de grãos (OLIVEIRA \& ZANOTTO, 2008).
A altura de inserção do primeiro cacho, nas cultivares 'IAC 80' e 'Al Guarany 2002', foi, em média, $20 \mathrm{~cm}$ mais alta na segunda que na primeira época de semeadura, enquanto isso foi de $15 \mathrm{~cm}$ na cultivar ‘BRS 188 Paraguaçu’ (Tabela 1). Entretanto, em outros trabalhos, a altura de inserção do primeiro racemo floral foi superior na semeadura de dezembro e janeiro e menor em semeadura mais tardia (REGO FILHO et al., 2006; SOUZA et al., 2007a). O atraso de semeadura também reduziu a eficiência de uso da água pela mamoneira, enquanto a antecipação aumentou o rendimento de grãos dessa planta (VIJAYA KUMAR et al., 1997). A antecipação da semeadura de março para janeiro, no Ceará, resultou em maior altura de inserção do racemo primário com irrigação (SOUZA et al., 2007b). O maior crescimento na segunda época de semeadura pode ser explicado pela maior precipitação durante a fase vegetativa da cultura, pois essa planta apresentou maior altura de inserção de racemo em condições irrigadas (KOUTROUBAS et al., 2000).

A terceira floração das cultivares 'IAC 226’, 'Al Guarany 2002' e 'BRS 188 Paraguaçu’, na segunda época de semeadura, foi antecipada em cerca de 20 dias. Nessa mesma época, a segunda floração da cultivar 'IAC 80' foi antecipada em 29 dias, o que pode ser reflexo do crescimento vegetativo mais acelerado das plantas, mas a terceira floração não ocorreu em nenhuma das épocas (Tabela 1). Plantas de mamona semeadas em dezembro e março floresceram mais cedo que aquelas semeadas em janeiro e fevereiro, devido ao fato de as chuvas de fevereiro terem sido acima da média, o que pode ter afetado o crescimento inicial dessa cultura e retardado o florescimento da mamoneira (SOUZA et al., 2007b).

Tabela 1 - Dias até a emergência (EM), altura da planta em cm (HP), altura de inserção do primeiro cacho em $\mathrm{cm}\left(\mathrm{H} 1^{\circ}\right)$, dias até a primeira, segunda e terceira floração $\left(1^{\mathrm{a}} \mathrm{Fl}, 2^{\mathrm{a}} \mathrm{Fl}\right.$ e $\left.3^{\mathrm{a}} \mathrm{Fl}\right)$ e dias até a primeira, segunda e terceira colheita $\left(1^{\mathrm{a}} \mathrm{Col}\right.$, $2^{\mathrm{a}} \mathrm{Col}$ e $\left.3^{\mathrm{a}} \mathrm{Col}\right)$, para diferentes cultivares de mamona cultivadas em duas épocas de semeadura (ES), no local 1 da Embrapa Clima Temperado, Pelotas, Rio Grande do Sul, 2007.

\begin{tabular}{|c|c|c|c|c|c|c|c|c|c|c|}
\hline Cultivares & ES & EM & HP & $\mathrm{H} 1^{\circ}$ & $1^{\mathrm{a}} \mathrm{Fl}$ & $2^{\mathrm{a}} \mathrm{Fl}$ & $3^{\mathrm{a}} \mathrm{Fl}$ & $1^{\mathrm{a}} \mathrm{Col}$ & $2^{\mathrm{a}} \mathrm{Col}$ & $3^{\mathrm{a}} \mathrm{Col}$ \\
\hline \multirow[t]{2}{*}{ 'IAC 226' } & $1^{\underline{a}}$ & $15 a^{*}$ & $118 \mathrm{~b}$ & $75 a$ & $36 a$ & $51 \mathrm{a}$ & $107 a$ & $84 \mathrm{~b}$ & $111 \mathrm{~b}$ & 213a \\
\hline & $2^{-\mathrm{a}}$ & $12 \mathrm{~b}$ & $237 a$ & $78 a$ & $40 \mathrm{a}$ & $61 \mathrm{a}$ & $81 \mathrm{~b}$ & $109 a$ & 179a & $228 a$ \\
\hline \multirow[t]{2}{*}{ 'IAC 80’ } & $1^{\underline{\underline{a}}}$ & $15 a$ & 62 b & $55 \mathrm{~b}$ & $55 a$ & $115 a$ & - & $103 \mathrm{~b}$ & $222 a$ & - \\
\hline & $2^{\underline{\mathrm{a}}}$ & $12 \mathrm{~b}$ & $217 a$ & $74 a$ & $60 a$ & $86 \mathrm{~b}$ & - & $135 a$ & $197 \mathrm{~b}$ & - \\
\hline \multirow[t]{2}{*}{ 'Al Guarany 2002’ } & $1^{\mathrm{a}}$ & $15 a$ & $93 \mathrm{~b}$ & $45 \mathrm{~b}$ & $39 a$ & $50 a$ & $108 \mathrm{a}$ & $89 \mathrm{~b}$ & $115 \mathrm{~b}$ & 213a \\
\hline & $2^{\mathrm{a}}$ & $12 \mathrm{~b}$ & $200 a$ & $67 a$ & $44 a$ & $49 a$ & $73 \mathrm{~b}$ & $113 a$ & $186 a$ & 231a \\
\hline \multirow[t]{2}{*}{ 'BRS 188 Paraguaçu' } & $1^{\underline{\underline{a}}}$ & $15 a$ & $105 \mathrm{~b}$ & 73a & $45 a$ & $52 \mathrm{~b}$ & $114 a$ & $105 \mathrm{~b}$ & $133 \mathrm{~b}$ & $217 a$ \\
\hline & $2^{\underline{\mathrm{a}}}$ & $12 \mathrm{~b}$ & $250 a$ & $88 a$ & $44 a$ & $69 a$ & $85 \mathrm{~b}$ & $120 \mathrm{a}$ & $197 a$ & $228 a$ \\
\hline CV (\%) & & 1,7 & 8,1 & 10,3 & 10,1 & 5,6 & 5,7 & 2,77 & 4,6 & 68 \\
\hline
\end{tabular}

* Médias nas colunas não seguidas de mesma letra, por coluna e dentro de cada cultivar, diferem pelo teste de Tukey, a 5\% de probabilidade. 
O período de colheita na segunda época de semeadura não foi antecipado, assim como ocorreu com as florações. A primeira colheita foi retardada em 20 dias, e a segunda, em 68 dias, para as quatro cultivares, exceto na segunda colheita da 'IAC 80'. O retardamento da terceira colheita das cultivares 'IAC 226' e 'Al Guarany 2002' foi de 15 e 18 dias, respectivamente, na segunda época de semeadura (Tabela 1).

A ocorrência de pragas e doenças variou com a época de semeadura (Tabela 2). O percevejo ocorreu somente na primeira época, sendo a cultivar 'IAC 80' a mais atacada (30\%). De modo semelhante, a mancha de cercospora foi mais intensa na primeira época de semeadura, quando a 'BRS 188 Paraguaçu' foi mais suscetível, com $48 \%$ de ataque, seguida da 'IAC 80 ', com 25\%. O ataque de percevejos não ocorreu na segunda época de semeadura, e a incidência de cercospora foi menor e somente as cultivares 'BRS 188 Paraguaçu' e 'IAC 80' foram atacadas.

As quatro cultivares tiveram a emergência antecipada na segunda época de semeadura, aos 15 dias no local 2, enquanto que na primeira epoca de semeadura daquele local foi aos 21 dias. De forma semelhante, a altura de plantas foi maior na segunda época de semeadura, quando a altura das cultivares 'IAC 226', 'IAC 80' e 'BRS 188 Paraguaçu' foi superior a dois metros e não ultrapassou 1,5 metros na primeira. Entretanto, essa cultivar tende a crescer mais que três metros, quando há boa disponibilidade de água, o que prejudica a produtividade e a colheita (SEVERINO et al., 2004). A altura de inserção do primeiro cacho foi $20 \mathrm{~cm}$ mais alta na segunda época nas cultivares 'IAC 226', 'IAC 80' e 'Al Guarany 2002’ (Tabela 3).
A maior velocidade de emergência e crescimento vegetativo, na segunda época de semeadura, possivelmente, está ligada a temperaturas mais elevadas, maior volume de precipitação e maior número de horas de insolação, durante a fase vegetativa da mamoneira. Contudo, o maior crescimento pode não ser vantajoso, pois o porte maior das plantas de mamona dificulta seu manejo, favorece o tombamento e cria microclima favorável à doença do mofo-cinzento.

A segunda e a terceira floração das cultivares 'IAC 226', 'Al Guarany 2002' e ‘BRS 188 Paraguaçu’ foram retardadas em 21 e 28 dias, na segunda época de semeadura, respectivamente, em relação à primeira (Tabela 3). Isso, possivelmente, retardará a formação das sementes que irão maturar no período chuvoso do outono, o que diminui a qualidade fisiológica e favorece a ocorrência do mofo-cinzento. Inferências sobre a colheita não puderam ser feitas, pois a produção de sementes foi extremamente prejudicada pelo mofo-cinzento, e o atraso da segunda época de semeadura pode prejudicar a produtividade de grãos e de óleo de mamona, pelo fato de que essas variáveis têm relação com a produtividade (SOUZA et al., 2007b).

$\mathrm{O}$ ataque de pragas e doenças no local 2 também foi influenciado pela época de semeadura, com o percevejo ocorrendo somente na primeira, mas com menor severidade. A cultivar 'IAC 80' foi a mais suscetível a esse inseto, com média de $10 \%$ de danos no cacho. As cultivares 'IAC 226’e 'Al Guarany 2002' apresentaram certa resistência à doença de cercospora, com poucos sintomas dessa doença em suas folhas. A menor incidência de mancha de cercospora no local 2 pode ser explicada pelo melhor

Tabela 2 - Percentagem de ataque de percevejos e ocorrência da mancha de cercospora em cultivares de mamona, segundo a época de semeadura, no local 1 da Embrapa Clima Temperado, Pelotas, Rio Grande do Sul, 2007.

\begin{tabular}{|c|c|c|c|}
\hline Cultivar & Época de semeadura & Ataque de percevejo & Mancha de cercospora \\
\hline \multirow[t]{2}{*}{ 'IAC 226' } & $1^{\mathrm{a}}$ & $8 a$ & $0 \mathrm{a}$ \\
\hline & $2^{\underline{a}}$ & 0 & 0a \\
\hline \multirow[t]{2}{*}{ 'IAC 80’ } & $1^{\mathrm{a}}$ & $30 \mathrm{a}$ & $25 a$ \\
\hline & $2^{\mathrm{a}}$ & $0 \mathrm{~b}$ & $9 b$ \\
\hline \multirow[t]{2}{*}{ ‘Al Guarany 2002’ } & $1^{\mathrm{a}}$ & $17 \mathrm{a}$ & $1 \mathrm{a}$ \\
\hline & $2^{\underline{a}}$ & ob & $0 \mathrm{a}$ \\
\hline \multirow[t]{2}{*}{ 'BRS 188 Paraguaçu’ } & $1^{\mathrm{a}}$ & $13 a$ & $48 a$ \\
\hline & $2^{\mathrm{a}}$ & $0 \mathrm{~b}$ & $13 b$ \\
\hline CV (\%) & & 106 & 66 \\
\hline
\end{tabular}

* Médias nas colunas não seguidas de mesma letra, por coluna e dentro de cada cultivar, diferem pelo teste de Tukey, a 5\% de probabilidade. 
Tabela 3 - Dias até a emergência (EM), altura da planta em cm (HP), altura de inserção do primeiro cacho em $\mathrm{cm}\left(\mathrm{H} 1^{\circ}\right)$, dias até a primeira, segunda e terceira floração (1 ${ }^{a} \mathrm{Fl}, 2^{\mathrm{a}} \mathrm{Fl}$ e $\left.3^{\mathrm{a}} \mathrm{Fl}\right)$ e dias até a primeira e segunda colheita (1 $1^{\mathrm{a}} \mathrm{Col}$ e $\left.2^{\mathrm{a}} \mathrm{Col}\right)$, para diferentes cultivares de mamona cultivadas em duas épocas de semeadura (ES), no local 2 da Embrapa Clima Temperado, Pelotas, Rio Grande do Sul, 2007

\begin{tabular}{|c|c|c|c|c|c|c|c|c|c|}
\hline Cultivares & ES & EM & HP & $\mathrm{H} 1^{\circ}$ & $1^{\mathrm{a}} \mathrm{Fl}$ & $2^{\mathrm{a}} \mathrm{Fl}$ & $3^{\mathrm{a}} \mathrm{Fl}$ & $1^{\mathrm{a}} \mathrm{Col}$ & $2^{\mathrm{a}} \mathrm{Col}$ \\
\hline \multirow[t]{2}{*}{ 'IAC 226' } & $1^{\underline{a}}$ & $21 \mathrm{a}$ & $150 \mathrm{~b}$ & $65 \mathrm{~b}$ & $34 a$ & $42 b$ & $58 b$ & $87 \mathrm{~b}$ & 102 \\
\hline & $2^{\underline{a}}$ & $15 \mathrm{~b}$ & $232 \mathrm{a}$ & $82 a$ & $42 a$ & $65 a$ & $86 a$ & 134a & - \\
\hline \multirow[t]{2}{*}{ 'IAC 80’ } & $1^{\mathrm{a}}$ & $21 \mathrm{a}$ & $85 b$ & $58 \mathrm{~b}$ & $48 a$ & $75 b$ & $57 a$ & $102 a$ & - \\
\hline & $2^{\underline{\mathrm{a}}}$ & $15 \mathrm{~b}$ & 203a & $81 \mathrm{a}$ & $58 a$ & $92 a$ & $0 \mathrm{~b}$ & $0 \mathrm{~b}$ & - \\
\hline \multirow[t]{2}{*}{ 'Al Guarany 2002' } & $1^{\underline{\mathrm{a}}}$ & $21 \mathrm{a}$ & $92 b$ & $35 \mathrm{~b}$ & $36 a$ & $40 \mathrm{~b}$ & $59 b$ & $90 \mathrm{~b}$ & 103 \\
\hline & $2^{\mathrm{a}}$ & $15 \mathrm{~b}$ & $177 \mathrm{a}$ & $55 a$ & $43 a$ & $60 \mathrm{a}$ & $87 a$ & $134 \mathrm{a}$ & - \\
\hline \multirow[t]{2}{*}{ 'BRS 188 Paraguaçu’ } & $1^{\underline{a}}$ & $21 \mathrm{a}$ & $132 b$ & $68 a$ & $41 \mathrm{a}$ & $48 \mathrm{~b}$ & $60 \mathrm{~b}$ & $102 b$ & 124 \\
\hline & $2^{\underline{\mathrm{a}}}$ & $15 \mathrm{~b}$ & $244 a$ & $75 a$ & $45 a$ & $74 a$ & $89 a$ & $134 a$ & - \\
\hline CV (\%) & & 2,5 & 7,4 & 18,8 & 7,3 & 4,6 & 2,72 & 0,2 & 6,5 \\
\hline
\end{tabular}

* Médias nas colunas não seguidas de mesma letra, por coluna e dentro de cada cultivar, diferem pelo teste de Tukey, a 5\% de probabilidade.

equilíbrio biológico do ambiente, pois esse local está em transição agroecológica (Tabela 4).

Mancha de cercospora e fusariose ocorreram na segunda época de semeadura, e essa última doença causa necroses nas raízes e no colo da planta, ocasionando seu tombamento. A cultivar 'IAC 80' foi mais suscetível ao fungo Fusarium sp., com $21 \%$ de plantas atacadas na segunda época de semeadura, enquanto a 'BRS 188 Paraguaçu' apresentou susceptibilidade na segunda época de semeadura, com $12 \%$ de plantas atacadas (Tabela 4).

As cultivares 'IAC 226' e 'Al Guarany 2002' foram mais suscetíveis ao mofo-cinzento que ao percevejo, à mancha de cercospora ou à fusariose. A cultivar 'IAC 226' foi a mais suscetível àquela doença na primeira época de semeadura, com $23 \%$ de plantas atacadas, seguida pela cultivar ' $\mathrm{Al}$
Guarany 2002', com 4\%. A ocorrência do mofocinzento foi maior na segunda época, com 32 e $10 \%$ de plantas das 'IAC 226' e 'Al Guarany 2002' danificadas, respectivamente (Tabela 4). A fusariose ocorreu somente no local 2, indicando interação dessa doença com o ambiente de cultivo, pois o solo desse local é mais argiloso e sua maior retenção de umidade favorece a ocorrência dessa doença.

\section{CONCLUSÕES}

O crescimento vegetativo das cultivares de mamona foi maior na segunda época de semeadura, mas esta atrasou as florações e colheita dessa planta. O local de cultivo e a época de semeadura condicionam as características morfológicas e o aparecimento de certas pragas e doenças na cultura da mamona.

Tabela 4 - Percentagem de ataque de percevejo, fusariose e mofo-cinzento em cultivares de mamona, segundo a época de semeadura, no local 2 da EMBRAPA Clima Temperado, Pelotas, Rio Grande do Sul, 2007.

\begin{tabular}{|c|c|c|c|c|}
\hline Cultivar & Época de semeadura & Percevejo & Fusariose & Mofo-cinzento \\
\hline \multirow[t]{2}{*}{ 'IAC 226' } & $1^{\mathrm{a}}$ & $1 \mathrm{a}$ & 0a & $23 a$ \\
\hline & $2^{\underline{a}}$ & $0 \mathrm{a}$ & $2 \mathrm{a}$ & $32 \mathrm{a}$ \\
\hline \multirow[t]{2}{*}{ 'IAC 80’ } & $1^{\mathrm{a}}$ & $10 \mathrm{a}$ & $0 \mathrm{~b}$ & 0a \\
\hline & $2^{\mathrm{a}}$ & ob & $21 \mathrm{a}$ & 0a \\
\hline \multirow[t]{2}{*}{ ‘Al Guarany 2002’ } & $1^{\mathrm{a}}$ & $4 a$ & 0a & $4 a$ \\
\hline & $2^{\underline{a}}$ & ob & $2 \mathrm{a}$ & $10 \mathrm{a}$ \\
\hline \multirow[t]{2}{*}{ 'BRS 188 Paraguaçu’ } & $1^{\mathrm{a}}$ & 0a & ob & $2 \mathrm{a}$ \\
\hline & $2^{\mathrm{a}}$ & 0a & $12 \mathrm{a}$ & $4 a$ \\
\hline CV (\%) & & 39,6 & 80,0 & 32,1 \\
\hline
\end{tabular}

* Médias não seguidas de mesma letra, por coluna e dentro de cada cultivar, diferem pelo teste de Tukey, a 5\% de probabilidade. 


\section{REFERÊNCIAS}

AMORIM NETO, M.S. et al. Clima e solo. In: AZEVEDO, D.M.P.; LIMA, E.F. O agronegócio da mamona no Brasil. Campina Grande: Embrapa Algodão; Brasília: Embrapa Informação Tecnológica, 2001. p.63-76

AZEVEDO, D.M.P. et al. Rendimento e eficiência agronômica do consórcio da mamoneira com cereais e feijão caupi no semi-árido nordestino. Revista Brasileira de Oleaginosas e Fibrosas, Campina Grande, v.11, n.3, p.145162, 2007. Disponível em: http://www.cnpa.embrapa.br/rbof/ fasciculos.php. Acesso em: 20 abr. 2009.

BELTRÃO, N.E.M. et al. Fitologia. In: AZEVEDO, D.M.P.; LIMA, E.F. O agronegócio da mamona no Brasil. Campina Grande: Embrapa Algodão; Brasília: Embrapa Informação Tecnológica, 2001. p.37-61

CORRÊA, M.L.P. et al. Comportamento de cultivares de mamona em sistemas de cultivo isolados e consorciados com caupi e sorgo granífero. Revista Ciência Agronômica, Fortaleza, v.37, n.2, p.200-207, 2006. Disponivel em: http://www.ccarevista.ufc.br/seer/index.php/ ccarevista/article/viewFile/201/195. Acesso em: 15 abr. 2009.

KHRYANIN, V.N. Role of phytohormones in sex differentiation in plants. Russian Journal of Plant Physiology, Moscow, v.49, n.4, p.545-551, 2002. Disponivel em: http://www.cnpa.embrapa.br/publicacoes/ 2005/BOLETIM60.pdf. Acesso em: 20 abr. 2009.

KOUTROUBAS, S.D. et al. Water requirements for castor oil crop (Ricinus communis L.) in a Mediterranean climate. Journal of Agronomy and Crop Science, Braunschweig, v.184, n.1, p.33-41, 2000. Disponível em: http:// www.ingentaconnect.com/content/bsc/jac/2000/00000184/ 00000001/art00005. Acesso em: 15 abr. 2009. doi: 10.1046/j.1439-037x.2000.00357.x.

MACHADO, A.A.; CONCEIÇÃO, A.R. Sistema de análise estatística para Windows. WinStat. Versão 2.0. Pelotas: UFPel, 2003. (Programa Computacional)

OLIVEIRA, I.J.; ZANOTTO, M.D. Eficiência da seleção recorrente para redução da estatura de plantas em mamoneira (Ricinus communis L.). Ciência e Agrotecnologia, Lavras, v.32, n.4, p.1107-1112, 2008. Disponível em: http://www.editora.ufla.br/revista/32_4/ (11)\%20Artigo\%204492.pdf. Acesso em: 15 abr. 2009.

QUEIROGA, V.P.; SANTOS, R.F. Diagnóstico da produção de mamona (Ricinus communis, L.) em uma amostra de produtores do nordeste brasileiro. Revista Brasileira de Oleaginosas e Fibrosas, Campina Grande, v.12, n.1, p.923, 2008. Disponível em: http:// www.infoteca.cnptia.embrapa.br/bitstream/CN PA2009_rbof,12(1),9-23,2008.pdf Acesso em: 20 abr. 2009. doi: $09 / 22224 / 1 / 1212008001$.

RAMOS, N.P. et al. Semeadura do híbrido Lyra de mamona (Ricinus communis L.) sob plantio direto. Ciência e Agrotecnologia, Lavras, v.32, n.2, p.481-486, 2008. Disponível em: http://www.scielo.br/ scielo.php?script=sci_arttext\&pid=S1413. Acesso em: 15 abr. 2009. doi: doi: 10.1590/S1413-70542008000200021.

RÊGO FILHO, L.M. et al. Avaliação de genótipos de mamona em Campos dos Goytacazes, região norte fluminense. In: CONGRESSO BRASILEIRO DE MAMONA, 2., 2006, Aracaju. Anais... Campina Grande: Embrapa Algodão, 2006. 1 CD-ROM.

SAVY FILHO, A. et al. Novo cultivar de mamona: IAC226 (Tabary). Bragantia, Campinas, v.49, n.2, p.269280, 1990.

SEVERINO, L.S. et al. Adubação química da mamoneira com NPK, cálcio, magnésio e micronutrientes em Quixeramobim, CE. In: CONGRESSO BRASILEIRO DE MAMONA: Energia e sustentabilidade, 2004, Campina Grande. Anais... Campina Grande: Embrapa Algodão, 2004. CD-ROM.

SOUZA, A.S. et al. Épocas de plantio e manejo de irrigação para a mamoneira. I - componentes da produção. Revista Ciência Agronômica, Fortaleza, v.38, n.4, p.414-421, 2007a. Disponivel em: http://ccarevista.ufc.br/seer/ index.php/ccarevista/article/view/103/98. Acesso em: 15 abr. 2009.

SOUZA, A.S. et al. Épocas de plantio e manejo de irrigação para a mamoneira. II - Crescimento e produtividade. Revista Ciência Agronômica, Fortaleza, v.38, n.4, p.422-429, 2007b. Disponivel em: http://ccarevista.ufc.br/ seer/index.php/ccarevista/article/view/104/99. Acesso em: 15 abr. 2009.

VIJAYA KUMAR, P. et al. Influence of moisture, thermal and photoperiodic regimes on the productivity of castor beans (Ricinus communis L.). Agricultural and Forest Meteorology, Christchurch, v.88, p.279-289, 1997. Disponível em: http://www.sciencedirect.com/ science?_ob=ArticleURL\&_udi=B6V8W-3SX70BXS\&_user. Acesso em: 20 abr. 2009. doi:10.1016/S01681923(97)00019-1. 